\title{
Inflammatory Bowel Diseases: What Do We Still Need to Investigate?
}

\author{
Marina Taus*, Debora Busni, Daniele Fumelli, Arianna Paci, Giulia Nicolai, Albano Nicolai \\ Dietetic and Clinical Nutrition Unit, Clinical Hospital of Ancona, Ancona, Italy \\ Email: ${ }^{*}$ marina.taus@ospedaliriuniti.marche.it
}

Received 15 September 2015; accepted 25 October 2015; published 28 October 2015

Copyright (C) 2015 by authors and Scientific Research Publishing Inc.

This work is licensed under the Creative Commons Attribution International License (CC BY).

http://creativecommons.org/licenses/by/4.0/

(c) (i)

Open Access

\begin{abstract}
Inflammatory bowel disease (IBD) including Crohn (CD) and ulcerative colitis (UC), is intestinal disorders with an unknown specific etiology. Many factors are involved in the pathogenesis: genetic, environment, nutrition, immunity and intestinal dysbiosis. In the present work, we review the most important trigger mechanisms involved in IBD, with a particular regard to the role of microbiota and fecal mass transplantation as a new therapeutic approach, that even if it can be considered safe and effective, data are necessary regarding all procedures not yet standardized and timing of treatment.
\end{abstract}

\section{Keywords}

Inflammatory Bowel Desease, Fecal Mass Transplantation, Nutrition and Macrobiota

\section{Nutrition}

It is well known that industrialized country is very exposed to CD for the western diet characterized by an high intake of calories, total fats, PUFAs, carbohydrate especially refined sugar, meat and at the same time low fiber, vegetable and fruit intakes. Several studies have shown that food sensitivity occurs in some CD patients especially against cereals, dairy products and yeast [1] [2]. Moreover, some evidences suggest that dietary factors such as poorly absorbed short chain carbohydrates and polyols, better known as FODMAPs particularly presented in the western diet, (fermentable oligo-di and mono saccharides and polyols), may play an important role in the etiopathogenesis of CD. The common dietary source of FODMAPs is fructose, fructans and galactooligosaccharides, all of these seem to increase the intestinal permeability, which is a predisposing factor of CD [3]. Recently, exclusion of FODMAPs from diet has been shown to improve functional gut symptom in IBD or irritable bowel syndrome patients [4]. It has been suggested that some dietary factors entail can enhance systemic

*Corresponding author.

How to cite this paper: Taus, M., Busni, D., Fumelli, D., Paci, A., Nicolai, G. and Nicolai, A. (2015) Inflammatory Bowel Diseases: What Do We Still Need to Investigate? Open Journal of Gastroenterology, 5, 146-154.

http://dx.doi.org/10.4236/ojgas.2015.510024 
and mucosal immunological reactivity against gut bacterial antigens resulting from complex interactions between environment and patient's genetic make up [5]; this immune reactivity seems to be due to a loss of tolerance to autologous enteric flora, resulting in an inappropriate immune response, which in turn leads to a development of a chronic inflammatory process in the intestinal mucosa that characterizes chronic diseases such as IBD, obesity, food intolerances and allergic pathologies, metabolic syndrome, or cancer.

As reported by David et al. [6], diet rapidly and reproducibly alters the human gut microbiome:

- The diet consisting of animal or vegetable products can quickly change the structure of the microbiome, overcoming the individual genetic differences;

- The diet based on animal products suggests a link between dietary fats, bile acids and growth of microorg-anisms that can trigger IBD;

- The gut microbiome responds to dietary modification quickly, overcoming the possible genetic predisposition.

\section{Genetic}

Another potential link and research focus between intestinal bacteria, immune response in CD is the role of Paneth cells (PC), specialized epithelial cells found in the intestinal crypts that secrete antimicrobial peptides to remove bacteria from mucosa. Defects in this defence mechanism, which are linked to autophagy and NOD2, can lead to continuous stimulation of the adaptative immune system by microbes that can access after diet related barrier disruption, not properly cleared from PC [7] [8].

Dietary components can alter certain types of gene expression and can become risk or protective factors for diseases development [9] [10]. For example multidrug resistance 1 is a probable IBD susceptibility gene that encodes a P-glycoprotein. It is vulnerable to inhibition, activation or induction by various herbal constituents; indeed while curcumin and piperine were found to inhibit P-glycoprotein, some green tea catechins were found to be activators of P-glycoprotein [11]. Some studies tested the ability of food components or extracts to overcome the functional effects of certain variant SNPs that may be important in IBD. Even if a personalized nutritional prescription based on individual genetic variations is important in the treatment of IBD, further studies are necessary to well define the nutrient-gene interaction [12].

There is also the relevant role of epigenetic defined as mitotically heritable changes in gene function not explained by changes in the DNA sequence, such as DNA metilation, RNA interferences, positioning of nucleosomes [13].

\section{Intestinal Permeability}

The single layer epithelium is an effective barrier against harmful macromolecules and microorganisms; it also remains permeable to nutrients and allows exposure of the mucosal immune system to food antigens and microbial factors [14]-[16]. Impairment in the function of the intestinal barrier leads to increased permeability to luminal antigens, which represents one of the crucial factors in the pathogenesis of IBD. Intestinal permeability is regulated by cytoskeleton adaptors (zonula occludens1, beta catenin) and transmembrane proteins (claudins, occludin, E-cadherin). Some factors, like composition of microbiota, could affect these mechanisms and the related permeability. Some studies have shown an important role of cytokines including tumor necrosis factor (TNF) alfa and interferon gamma in increasing permeability of tight junctions in intestinal epithelial cells [17]-[19]. Although it is well known that increased permeability is characteristic of acute CD, it is not yet demonstrated if this is consequence of inflammation or a primary cause of the disease.

\section{Immune Response}

Disregulation of the innate immune response to luminal microbial or nutritional antigens seems to play a major role especially in the pathogenesis of $\mathrm{CD}$. The proinflammatory response is characterized by the secretion of TNF alfa, interferon-gamma, interleukin -12 and 23 in response to exposure to bacterial products and microbial biofilms may trigger an abnormal adaptative immune response [1].

The ethiopathogenesis of IBD could be hypothesized as following. FODMAPs with their prebiotic effect, other dietary factors (i.e. gliadin), saturated fatty acids, food additives, toothpaste (aluminosilicicates), pathogen associated molecular patterns (PAMPs), or infections change intestinal permeability and microbioma by disrupting apical junctional complexes or damage the protective mucosal layer [1] [20]. These mechanisms lead to an increased exposure of bacterial products, with an increased immune stimulation and activation of adaptive 
immunity, which in turn leads to a loss of tolerance to autologous enteric flora, for aberrant immune response and inflammation as observed in rats [21]-[23].

Moreover as reported by Kao et al. [24] in according to the hygiene hypothesis of Gearry RB [4], exposure to fewer microbes and less microbial communities at early age may lead to development of immune system less able to "tolerate" exposure to microbial laden environment later in life leading to inappropriate immune activation. Increased use of antibiotics at young age may also contribute to reduced microbiota diversity and development of IBD.

What about microbiota, one of or the most important key factor in the pathogenesis of IBD?

An increasing numbers of publications regarding intestinal microbiota are performed in the last years showing the link between microbiota-microbioma (bacterial genetic profile), food, immune system, central nervous system and chronic diseases such as IBD.

Although a unique or specific bacterial species has not been identified as a single cause of increased permeability in human IBD, several species such as adherent invasive Escherichia Coli (AIEC) have been shown to impair permeability [22]-[25], characteristic of active CD. Anyway it is unclear whether this is a secondary phenomenon because of inflammation or a primary cause of disease. Many findings indicate that a leaky gut may precede CD, or be environmentally induced, representing the complex role of permeability defects in IBD pathogenesis.

By analysis of Crohn patients gut microbiota a decrease in the abundance and biodiversity of intestinal bacteria within the dominant phylum Firmicutes has been observed [26]. In particular Sokol et al. [27] found a reduction of the major member of Firmicutes, Faecalibacterium prausnitzii, on resected ileal Crohn mucosa, associated with endoscopic recurrence at 6 months. It has been observed in vitro peripheral blood mononuclear cell stimulation by Faecalibacterium Prausnitzii that led to a significant decrease in IL-12 and IFN- $\gamma$ production levels and higher secretion of IL-10.

These results have been confirmed by Ramirez-Farias in 2009 [28], that demonstrated that F. prausnitzii exhibits anti-inflammatory effects on cellular and TNBS colitis models, partly due to secreted metabolites able to block NF-kappaB activation and IL-8 production. These results suggest that counterbalancing dysbiosis using $F$. prausnitzii as a probiotic is a promising strategy in CD treatment.

A recent paper of Schaubeck, M. [29] has put in evidence that dysbiotic gut microbiota causes transmissible Crohn's disease like ileitis independent of failure in antimicrobial defence. It is known that Paneth cell, located in the crypt base of the small intestine, produce antimicrobial peptides (lysozime); the loss of their function is associated with ileal phenotypes of CD. Schaubeck et al. [29] observed that transfer of dysbiotic microbiota to germ free recipients causes Crohn disease like inflammation in genetically susceptible recipients and the loss of Paneth cells function is subsequent to the development of ileitis in mice. This study helps to elucidate the therapeutic relevance of microbiota transplantation in Crohn's disease.

\section{Direct Influence of Nutrition on the Intestinal Microbiome and Permeability}

Diet consisting of animal or vegetable products is able to quickly change the structure, surpassing the microbiome individual genetic differences. The diet based on animal products, is to assume a link between dietary fats, bile acids and growth of microorganisms able to unleash IBD [6].

It has been hypothesized that specific food compounds can disrupt apical junctional complexes (as gliadin or sodium caprate) or damage the protective mucus layer. Saturated milk fat can alter microbiome by increasing the taurine conjugation of bile acids with a secondary inflammation as observed in rats [1]. Other dietary factors have been shown to promote bacterial translocation and food antigens penetration, with activation of adaptive immunity. Carboxymethylcellulose of industrialized milk products, breads, sausages, sauces, has been shown to enable bacterial adherence to intestinal epithelium.

As mentioned by Guagnozzi, D. et al. [12] there are exogenous dietary microparticles (non biological) with an appropriate size and shape which are taken up by mucosal phagocytes, such as food additives, tooth paste (aluminosilicicates), pharmaceuticals. These exogenous microparticles absorb certain antigenic luminal materials such as pathogen-associated molecular patterns (PAMPs) and then carry these PAMPs to the intestinal tissue. These processes seem to induce an abnormal immune response characterized by a reduction of physiological immune tolerance of the intestinal mucosa which leads to a chronic inflammation. [1] [20].

\section{How Can We Treat IBD?}

Going from less invasive and safer to more invasive and less safe treatment, and from less effective to more ef- 
fective treatment [30] we have:

- diet (FODMAPs, exclusion diet);

- prebiotics;

- probiotics;

- artificial nutrition, like enteral formula enriched in TGFbeta2 [31], or parenteral nutrition [32];

- biological treatments;

- drugs (steroids, ASA, loperamide);

- intestinal resections;

- ... the "new entry treatment": the fecal mass transplantation (FMT).

There are many studies regarding of pharmacological and biological treatments [33] [34] whose efficacy and limits are well known as well as the benefical aspects of pre and probiotics [35]-[37].

Enteral nutrition (EN), the primary nutrition treatment, is considered less effective than corticosteroids [38][41], as shown in different meta-analyses and original publication; nevertheless data demonstrate that EN is effective in inducing remission of IBD especially in CD, and suppressing the postoperative Crohn's disease recurrence [40]

D'Argenio et al. [41] have shown that EN is able to normalize the altered gut microbioma profile especially the ileum level of bacteriodetes, firmicutes and proteobacteria, confirming the altered intestinal microbiome profile and its relationship with nutrition. About enriched enteral formula it is well demonstrated that EN with TGFbeta2 is effective in the treatment of CD especially in children [42], even if further studies are necessary to confirm these data. Glutamine supplementation reduces intestinal damage and improves disease behaviour in animals [43]; however no RCTs have been able to demonstrate the real additional benefits for glutamine supplementation [44].

\section{Fecal Mass Transplantation (FMT): The Future}

Many studies were performed on FMT in IBD especially in UC.

In 1989, Bennet et al. documented the complete clinical remission in UC, after fecal retention enemas [45]; in the same year Borody and collegues "cured" 20 of 55 patients with IBD treated with FMT [46]. Many studies have been performed on FMT, also called stool/fecal transplantation, or fecal bacteriotherapy till now [47]-[51]. Most of them showed efficacy in term of remission, symptoms, treating CD infection, or restoring of intestinal microbiota. Most common adverse events include diarrhea on the day of administration, abdominal pain, belching or constipation. Few serious adverse events occur during treatment, but it is noteworthy that IBD related symptoms can be aggravated by FMT, in some case [52]-[57]. In 2012, a systematic review of FMT for IBD showed symptom improvement, remission, and cessation of medication after FMT treatment [50]. Other important observation was performed by Kao [24]: untapped power of normal luminal flora to inhibit even the most severe inflammation of Crohn's colitis, in contrast with the previous theory that IBD were considered the consequence of inappropriate activation of mucosal immune system driven by the presence of normal luminal flora.

However as reviewed by Ianiro et al. [58] after selecting 152 articles regarding FMT in IBD, some important observations were highlighted. None articles reported the complete methodology of FMT procedure, in most studies patients received multiple fecal infusions, by enema, colonscopy, or the combination of them. Fecal quantity varied from 30 to $300 \mathrm{~g}$ diluted in saline solution. Most donors underwent a viral screening, as well as stool tests for Clostridium difficile toxin, parasites, ova and bacterial pathogens. Fecal donors included healthy related and unrelated individuals. They conclude by saying that FMT is a safe procedure. Resolution or reduction of symptoms was reported in 71\% of IBD patients (both UC and CD). In two small prospective studies investigating the use of FMT in UC refractory to medical therapy, none of enrolled patients achieved clinical remission, but a short improvement of symptoms [59]. With an average of 91\% success rate, the FMT is considered an effective intervention for recurrent infection by Clostridium difficile.

In the study of Angelberger [55] FMT provide a temporary increase of phylotypes richness that was similar to donor microbiota; changes of gut microbiota after FMT confirm the potential therapeutic role of this treatment for IBD as observed by Cammarota et al. [60].

Nevertheless some questions remain open:

1) Why some people respond quickly to FMT with a clinical improvement and others are no responders?

2) Why some patients respond so impressively after a single FMT and others fail to do so?

3) Is FTM more effective in case of short disease duration? 


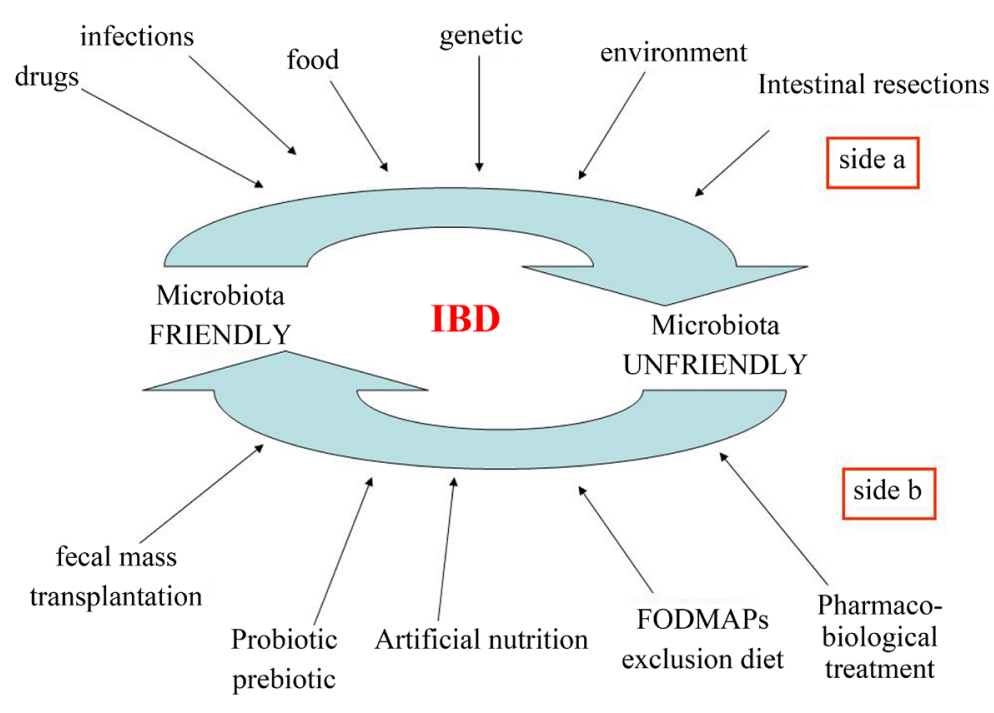

Figure 1. Mechanisms involved in the ethiopathogenesis (side a) and in the treatment (side b) of IBD, by influencing intestinal microbiota composition.

4) Donor characteristics are equally very important too, especially donor's microbial profile.

5) The long-term follow up data of FMT such as infections, intestinal inflammation and tumors are still lacking and need to be investigated.

6) We have also some impediments that limit FMT use in IBD, such as ethical and social issues, poor screening of donors, no standard administration of FMT, no standardized preparation of fecal samples, risk of dangerous side effects are not completely investigated.

7) Fresh vs. frozen stool vs. capsules: what is better?

8) Volume and route of fecal material administration especially in children.

So further studies are necessary to exclude that FMT could be a fancy trend [61].

The most relevant factors involved in the etiopathogenesis (side a) and treatment (side b) of IBD are reported in Figure 1.

\section{Conclusions}

It is not yet clearly demonstrated if dysbiosis causes inflammation or it is a consequence of it (or both). The genetic damages are observed as well as immunological alterations both that innate and adaptative. Several studies are investigating the different branches of the pathogenesis of IBD in order to treat all of them. Food and artificial nutrition have been observed to be able to modulate both intestinal microbiota and immune system; therefore, we have to investigate more and more nutrigenomic field.

Confirming data on restoring the microbiome as a treatment of IBD is mandatory, although many studies agree on the anti-inflammatory properties of $F$. prausnitzii as well as the necessity of increasing bifidobacteria.

Duration of remission after FMT, volume, formulation, and characteristics related to the donor, doses and methods of extraction of FM is still unclear and deserve confirmations, but particular attention has to be paid to the FMT in children.

However we have to better understand the relationships between the different fields of research inducing exacerbation or remission of IBD and the timing of the different intervention treatments.

\section{References}

[1] Levine, A. and Wine, E. (2013) Effects of Enteral Nutrition on Crohn's Disease: Clues to the Impact of Diet on Disease Pathogenesis. Inflammatory Bowel Diseases, 19, 1322-1329. http://dx.doi.org/10.1097/MIB.0b013e3182802acc

[2] Riordan, A.M., Hunter, J.O., Cowan, R.E., Crampton, J.R., Davidson, A.R., Dickinson, R.J., Dronfield, M.W., Fellows, I.W., Hishon, S., Kerrigan, G.N., et al. (1993) Treatment of Active Crohn’s Disease by Exclusion Diet: East Anglian Multicentre Controlled Trial. The Lancet, 342, 1131-1134. http://dx.doi.org/10.1016/0140-6736(93)92121-9

[3] Gibson, P.R. and Shepherd, S.J. (2005) Personal View: Food for Thought-Western Lifestyle and Susceptibility to 
Crohn's Disease. The FODMAP Hypothesis. Alimentary Pharmacology \& Therapeutics, 21, 1399-1409. http://dx.doi.org/10.1111/j.1365-2036.2005.02506.x

[4] Gearry, R.B., Irving, P.M., Barrett, J.S., Nathan, D.M., Shepherd, S.J. and Gibson, P.R. (2009) Reduction of Dietary Poorly Absorbed Short-Chain Carbohydrates (FODMAPs) Improves Abdominal Symptoms in Patients with Inflammatory Bowel Disease-A Pilot Study. Journal of Crohn's and Colitis, 3, 8-14. http://dx.doi.org/10.1016/j.crohns.2008.09.004

[5] Danese, S. and Fiocchi, C. (2006) Etiopathogenesis of Inflammatory Bowel Diseases. World Journal of Gastroenterology, 12, 4807-4812.

[6] David, L.A., Maurice, C.F., Carmody, R.N., Gootenberg, D.B., Button, J.E., Wolfe, B.E., Ling, A.V., Devlin, A.S., Varma, Y., Fischbach, M.A., Biddinger, S.B., Dutton, R.J. and Turnbaugh, P.J. (2014) Diet Rapidly and Reproducibly Alters the Human Gut Microbiome. Nature, 505, 559-563. http://dx.doi.org/10.1038/nature12820

[7] Cadwell, K., Patel, K.K., Maloney, N.S., Liu, T.C., Ng, A.C., Storer, C.E., Head, R.D., Xavier, R., Stappenbeck, T.S. and Virgin, H.W. (2010) Virus-Plus-Susceptibility Gene Interaction Determines Crohn's Disease Gene Atg16L1 Phenotypes in Intestine. Cell, 141, 1135-1145. http://dx.doi.org/10.1016/j.cell.2010.05.009

[8] Caprilli, R., Lapaquette, P. and Darfeuille-Michaud, A. (2010) Eating the Enemy in Crohn's Disease: An Old Theory Revisited. Journal of Crohn's and Colitis, 4, 377-383. http://dx.doi.org/10.1016/j.crohns.2010.05.007

[9] Cho, J.H. (2008) The Genetics and Immunopathogenesis of Inflammatory Bowel Disease. Nature Reviews Immunology, 8, 458-466. http://dx.doi.org/10.1038/nri2340

[10] Lee, G. and Buchman, A.L. (2009) DNA-Driven Nutritional Therapy of Inflammatory Bowel Disease. Nutrition, 25, 885-891. http://dx.doi.org/10.1016/j.nut.2009.06.011

[11] Zhou, S.F., Lim, L.Y. and Chowbay, B. (2004) Herbal Modulation of P-Glycoprotein. Drug Metabolism Reviews, 36, 57-104. http://dx.doi.org/10.1081/DMR-120028427

[12] Guagnozzi, D., González-Castillo, S., Olveira, A. and Lucendo, A.J. (2012) Nutritional Treatment in Inflammatory Bowel Disease. An Update. Revista Española de Enfermedades Digestivas, 104, 479-488. http://dx.doi.org/10.4321/S1130-01082012000900006

[13] Ventham, N.T., Kennedy, N.A., Nimmo, E.R. and Satsangi, J. (2013) Beyond Gene Discovery in Inflammatory Bowel Disease: The Emerging Role of Epigenetics. Gastroenterology, 145, 293-308. http://dx.doi.org/10.1053/j.gastro.2013.05.050

[14] Clayburgh, D.R., Shen, L. and Turner, J.R. (2004) A Porous Defense: The Leaky Epithelial Barrier in Intestinal Disease. Laboratory Investigation, 84, 282-291. http://dx.doi.org/10.1038/labinvest.3700050

[15] Collett, A., Higgs, N.B., Gironella, M., Zeef, L.A., Hayes, A., Salmo, E., Haboubi, N., Iovanna, J.L., Carlson, G.L. and Warhurst, G. (2008) Early Molecular and Functional Changes in Colonic Epithelium That Precede Increased Gut Permeability during Colitis Development in Mdr1a(-/-) Mice. Inflammatory Bowel Diseases, 14, 620-631. http://dx.doi.org/10.1002/ibd.20375

[16] Clemente, J.C., Ursell, L.K., Parfrey, L.W. and Knight, R. (2012) The Impact of the Gut Microbiota on Human Health: An Integrative View. Cell, 148, 1258-1270. http://dx.doi.org/10.1016/j.cell.2012.01.035

[17] Vetrano, S., Rescigno, M., Cera, M.R., Correale, C., Rumio, C., Doni, A., Fantini, M., Sturm, A., Borroni, E., Repici, A., Locati, M., Malesci, A., Dejana, E. and Danese, S. (2008) Unique Role of Junctional Adhesion Molecule-A in Maintaining Mucosal Homeostasis in Inflammatory Bowel Disease. Gastroenterology, 135, 173-184. http://dx.doi.org/10.1053/j.gastro.2008.04.002

[18] Sartor, R.B. (2008) Microbial Influences in Inflammatory Bowel Diseases. Gastroenterology, 134, 577-594. http://dx.doi.org/10.1053/j.gastro.2007.11.059

[19] Wang, F., Graham, W.V., Wang, Y., Witkowski, E.D., Schwarz, B.T. and Turner, J.R. (2005) Interferon-Gamma and Tumor Necrosis Factor-Alpha Synergize to Induce Intestinal Epithelial Barrier Dysfunction by Up-Regulating Myosin Light Chain Kinase Expression. The American Journal of Pathology, 166, 409-419. http://dx.doi.org/10.1016/S0002-9440(10)62264-X

[20] Lomer, M.C., Harvey, R.S., Evans, S.M., Thompson, R.P. and Powell, J.J. (2001) Efficacy and Tolerability of a Low Microparticle Diet in a Double Blind, Randomized, Pilot Study in Crohn's Disease. European Journal of Gastroenterology \& Hepatology, 13, 101-106. http://dx.doi.org/10.1097/00042737-200102000-00003

[21] Barrett, J.C., Hansoul, S., Nicolae, D.L., Cho, J.H., Duerr, R.H., Rioux, J.D., Brant, S.R., Silverberg, M.S., et al. (2008) Genome-Wide Association Defines More than 30 Distinct Susceptibility Loci for Crohn's Disease. Nature Genetics, 40, 955-962. http://dx.doi.org/10.1038/ng.175

[22] Peeters, H., Bogaert, S., Laukens, D., Rottiers, P., De Keyser, F., Darfeuille-Michaud, A., Glasser, A.L., Elewaut, D. and De Vos, M. (2007) CARD15 Variants Determine a Disturbed Early Response of Monocytes to Adherent-Invasive Escherichia coli Strain LF82 in Crohn's Disease. International Journal of Immunogenetics, 34, 181-191. 
http://dx.doi.org/10.1111/j.1744-313X.2007.00670.x

[23] Cho, J.H. and Weaver, C.T. (2007) The Genetics of Inflammatory Bowel Disease. Gastroenterology, 133, $1327-1339$. http://dx.doi.org/10.1053/j.gastro.2007.08.032

[24] Kao, D., Hotte, N., Gillevet, P. and Madsen, K. (2014) Fecal Microbiota Transplantation Inducing Remission in Crohn's Colitis and the Associated Changes in Fecal Microbial Profile. Journal of Clinical Gastroenterology, 48, 625628. http://dx.doi.org/10.1097/MCG.0000000000000131

[25] Wine, E., Ossa, J.C., Gray-Owen, S.D. and Sherman, P.M. (2009) Adherent-Invasive Escherichia coli, Strain LF82 Disrupts Apical Junctional Complexes in Polarized Epithelia. BMC Microbiology, 9, 180. http://dx.doi.org/10.1186/1471-2180-9-180

[26] Wang, Z.K., Yang, Y.S., Chen, Y., Yuan, J., Sun, G. and Peng, L.H. (2014) Intestinal Microbiota Pathogenesis and Fecal Microbiota Transplantation for Inflammatory Boweldisease. World Journal of Gastroenterology, 20, 1480514820. http://dx.doi.org/10.3748/wjg.v20.i40.14805

[27] Sokol, H., Pigneur, B., Watterlot, L., Lakhdari, O., Bermúdez-Humarán, L.G., Gratadoux, J.J., Blugeon, S., Bridonneau, C., Furet, J.P., Corthier, G., Grangette, C., Vasquez, N., Pochart, P., Trugnan, G., Thomas, G., Blottière, H.M., Doré, J., Marteau, P., Seksik, P. and Langella, P. (2008) Faecalibacterium prausnitzii Is an Anti-Inflammatory Commensal Bacterium Identified by Gut Microbiota Analysis of Crohn Disease Patients. Proceedings of the National Academy of Sciences of the United States of America, 105, 16731-16736. http://dx.doi.org/10.1073/pnas.0804812105

[28] Ramirez-Farias, C., Slezak, K., Fuller, Z., Duncan, A., Holtrop, G. and Louis, P. (2009) Effect of Inulin on the Human Gut Microbiota: Stimulation of Bifidobacterium adolescentis and Faecalibacterium prausnitzii. British Journal of Nutrition, 101, 541-550. http://dx.doi.org/10.1017/S0007114508019880

[29] Schaubeck, M., Clavel, T., Calasan, J., Lagkouvardos, I., Haange, S.B., Jehmlich, N., Basic, M., Dupont, A., Hornef, M., Bergen, M.V., Bleich, A. and Haller, D. (2015) Dysbiotic Gut Microbiota Causes Transmissible Crohn’s DiseaseLike Ileitis Independent of Failure in Antimicrobial Defence. Gut, 0, 1-13. http://dx.doi.org/10.1136/gutjnl-2015-309333

[30] Simrén, M., Barbara, G., Flint, H.J., Spiegel, B.M., Spiller, R.C., Vanner, S., Verdu, E.F., Whorwell, P.J. and Zoetendal, E.G., Rome Foundation Committee (2013) Intestinal Microbiota in Functional Bowel Disorders: A Rome Foundation Report. Gut, 62, 159-176. http://dx.doi.org/10.1136/gutjnl-2012-302167

[31] Marafini, I., Zorzi, F., Codazza, S., Pallone, F. and Monteleone, G. (2013) TGF-Beta Signaling Manipulation as Potential Therapy for IBD. Current Drug Targets, 14, 1400-1404. http://dx.doi.org/10.2174/13894501113149990157

[32] Triantafillidis, J.K. and Papalois, A.E. (2014) The Role of Total Parenteral Nutrition in Inflammatory Bowel Disease: Current Aspects. Scandinavian Journal of Gastroenterology, 49, 3-14. http://dx.doi.org/10.3109/00365521.2013.860557

[33] Annaházi, A. and Molnár, T. (2015) Optimal Endpoint of Therapy in IBD: An Update on Factors Determining a Successful Drug Withdrawal. Gastroenterology Research and Practice, 2015, Article ID: 832395. http://dx.doi.org/10.1155/2015/832395

[34] Johnson, S.L., Bartels, C.M., Palta, M., Thorpe, C.T., Weiss, J.M. and Smith, M.A. (2015) Biological and Steroid Use in Relationship to Quality Measures in Older Patients with Inflammatory Bowel Disease: A US Medicare Cohort Study. BMJ Open, 5, e008597. http://dx.doi.org/10.1136/bmjopen-2015-008597

[35] Delzenne, N.M., Neyrinck, A.M. and Cani, P.D. (2011) Modulation of the Gut Microbiota by Nutrients with Prebiotic Properties: Consequences for Host Health in the Context of Obesity and Metabolic Syndrome. Microbial Cell Factories, 10, S10. http://dx.doi.org/10.1186/1475-2859-10-s1-s10

[36] Sinagra, E., Tomasello, G., Cappello, F., Leone, A., Cottone, M., Bellavia, M., Rossi, F., Facella, T., Damiani, P., Zeenny, M.N., Damiani, F., Abruzzo, A., Damiano, G., Palumbo, V.D., Cocchi, M., Jurjus, A., Spinelli, G., Lo Monte, A.I. and Raimondo, D. (2013) Probiotics, Prebiotics and Symbiotics in Inflammatory Bowel Diseases: State-of-the-Art and New Insights. Journal of Biological Regulators \& Homeostatic Agents, 27, 919-933.

[37] Veerappan, G.R., Betteridge, J. and Young, P.E. (2012) Probiotics for the Treatment of Inflammatory Bowel Disease. Current Gastroenterology Reports, 14, 324-333. http://dx.doi.org/10.1007/s11894-012-0265-5

[38] Alhagamhmad, M.H., Day, A.S., Lemberg, D.A. and Leach, S.T. (2012) An Update of the Role of Nutritional Therapy in the Management of Crohn’s Disease. Journal of Gastroenterology, 47, 872-882. http://dx.doi.org/10.1007/s00535-012-0617-9

[39] Zachos, M., Tondeur, M. and Griffiths, A.M. (2007) Enteral Nutritional Therapy for Induction of Remission in Crohn's Disease. Cochrane Database of Systematic Reviews, No. 1, Article No.: CD000542. http://dx.doi.org/10.1002/14651858.cd000542.pub2

[40] Yamamoto, T., Shiraki, M., Nakahigashi, M., Umegae, S. and Matsumoto, K. (2013) Enteral Nutrition to Suppress Postoperative Crohn's Disease Recurrence: A Five-Year Prospective Cohort Study. International Journal of Colorectal 
Disease, 28, 335-340. http://dx.doi.org/10.1007/s00384-012-1587-3

[41] D’Argenio, V., Precone, V., Casaburi, G., Miele, E., Martinelli, M., Staiano, A., Salvatore, F. and Sacchetti, L. (2013) An Altered Gut Microbiome Profile in a Child Affected by Crohn's Disease Normalized after Nutritional Therapy. The American Journal of Gastroenterology, 108, 851-852. http://dx.doi.org/10.1038/ajg.2013.46

[42] Hartman, C., Berkowitz, D., Weiss, B., Shaoul, R., Levine, A., Adiv, O.E., Shapira, R., Fradkin, A., Wilschanski, M., Tamir, A. and Shamir, R. (2008) Nutritional Supplementation with Polymeric Diet Enriched with Transforming Growth Factor-Beta 2 for Children with Crohn's Disease. The Israel Medical Association Journal, 10, 503-507.

[43] Benjamin, J., Makharia, G., Ahuja, V., Anand Rajan, K.D., Kalaivani, M., Gupta, S.D. and Joshi, Y.K. (2012) Glutamine and Whey Protein Improve Intestinal Permeability and Morphology in Patients with Crohn's Disease: A Randomized Controlled Trial. Digestive Diseases and Sciences, 57, 1000-1012. http://dx.doi.org/10.1007/s10620-011-1947-9

[44] Ockenga, J., Borchert, K., Stüber, E., Lochs, H., Manns, M.P. and Bischoff, S.C. (2005) Glutamine-Enriched Total Parenteral Nutrition in Patients with Inflammatory Bowel Disease. European Journal of Clinical Nutrition, 59, 13021309. http://dx.doi.org/10.1007/s10620-011-1947-9

[45] Bennet, J.D. and Brinkman, M. (1989) Treatment of Ulcerative Colitis by Implantation of Normal Colonic Flora. Lancet, 333, 164. http://dx.doi.org/10.1016/S0140-6736(89)91183-5

[46] Borody, T.J., George, L., Andrews, P., Brandl, S., Noonan, S., Cole, P., Hyland, L., Morgan, A., Maysey, J. and Moore-Jones, D. (1989) Bowel-Flora Alteration: A Potential Cure for Inflammatory Bowel Disease and Irritable Bowel Syndrome? Medical Journal of Australia, 150, 604.

[47] Borody, T.J., Finlayson, S. and Paramsothy, S. (2014) Is Crohn’s Disease Ready for Fecal Microbiota Transplantation? Journal of Clinical Gastroenterology, 48, 582-583. http://dx.doi.org/10.1097/MCG.0000000000000155

[48] Borody, T.J., Warren, E.F., Leis, S.M., Surace, R., Ashman, O. and Siarakas, S. (2004) Bacteriotherapy Using Fecal Flora: Toying with Human Motions. Journal of Clinical Gastroenterology, 38, 475-483. http://dx.doi.org/10.1097/01.mcg.0000128988.13808.dc

[49] Borody, T.J., Warren, E.F., Leis, S., Surace, R. and Ashman, O. (2003) Treatment of Ulcerative Colitis Using Fecal Bacteriotherapy. Journal of Clinical Gastroenterology, 37, 42-47. http://dx.doi.org/10.1097/00004836-200307000-00012

[50] Anderson, J.L., Edney, R.J. and Whelan, K. (2012) Systematic Review: Faecal Microbiota Transplantation in the Management of Inflammatory Bowel Disease. Alimentary Pharmacology \& Therapeutics, 36, 503-516. http://dx.doi.org/10.1111/j.1365-2036.2012.05220.x

[51] Allegretti, J.R. and Hamilton, M.J. (2014) Restoring the Gut Microbiome for the Treatment of Inflammatory Bowel Diseases. World Journal of Gastroenterology, 20, 3468-3474. http://dx.doi.org/10.3748/wjg.v20.i13.3468

[52] Borody, T.J. and Campbell, J. (2012) Fecal Microbiota Transplantation: Techniques, Applications, and Issues. Gastroenterology Clinics of North America, 41, 781-803. http://dx.doi.org/10.1016/j.gtc.2012.08.008

[53] Petrof, E.O., Gloor, G.B., Vanner, S.J., Weese, S.J., Carter, D., Daigneault, M.C., Brown, E.M., Schroeter, K. and Allen-Vercoe, E. (2013) Stool Substitute Transplant Therapy for the Eradication of Clostridium difficile Infection: "RePOOPulating” the Gut. Microbiome, 1, 3. http://dx.doi.org/10.1186/2049-2618-1-3

[54] Allen-Vercoe, E., Reid, G., Viner, N., Gloor, G.B., Hota, S., Kim, P., Lee, C., O’Doherty, K., Vanner, S.J., Weese, J.S. and Petrof, E.O. (2012) A Canadian Working Group Report on Fecal Microbial Therapy: Microbial Ecosystems Therapeutics. The Canadian Journal of Gastroenterology, 26, 457-462.

[55] Angelberger, S., Reinisch, W., Makristathis, A., Lichtenberger, C., Dejaco, C., Papay, P., Novacek, G., Trauner, M., Loy, A. and Berry, D. (2013) Temporal Bacterial Community Dynamics Vary among Ulcerative Colitis Patients after Fecal Microbiota Transplantation. The American Journal of Gastroenterology, 108, 1620-1630.

http://dx.doi.org/10.1038/ajg.2013.257

[56] De Leon, L.M., Watson, J.B. and Kelly, C.R. (2013) Transient Flare of Ulcerative Colitis after Fecal Microbiota Transplantation for Recurrent Clostridium difficile Infection. Clinical Gastroenterology and Hepatology, 11, 10361038. http://dx.doi.org/10.1016/j.cgh.2013.04.045

[57] Schwartz, M., Gluck, M. and Koon, S. (2013) Norovirus Gastroenteritis after Fecal Microbiota Transplantation for Treatment of Clostridium difficile Infection Despite Asymptomatic Donors and Lack of Sick Contacts. The American Journal of Gastroenterology, 108, 1367. http://dx.doi.org/10.1038/ajg.2013.164

[58] Ianiro, G., Bibbiò, S., Scaldaferri, F., Gasbarrini, A. and Cammarota, G. (2014) Fecal Microbiota Transplantation in Inflammatory Bowel Disease: Beyond the Excitement. Medicine, 93, e97. http://dx.doi.org/10.1097/MD.0000000000000097

[59] Moayyedi, P., Surette, M.G., Kim, P.T., Libertucci, J., Wolfe, M., Onischi, C., Armstrong, D., Marshall, J.K., Kassam, Z., Reinisch, W. and Lee, C.H. (2015) Fecal Microbiota Transplantation Induces Remission in Patients with Active 
Ulcerative Colitis in a Randomized Controlled Trial. Gastroenterology, 149, 102.e6-109.e6. http://dx.doi.org/10.1053/j.gastro.2015.04.001

[60] Cammarota, G., Ianiro, G., Cianci, R., Bibbiò, S., Gasbarrini, A. and Currò, D. (2015) The Involvment of Gut Microbiota in Inflammatory Bowel Disease Pathogenesis: Potential for Therapy. Pharmacology \& Therapeutics, 149, 191212. http://dx.doi.org/10.1016/j.pharmthera.2014.12.006

[61] Vandenplas, Y., Pierard, D. and De Greef, E. (2015) Fecal Microbiota Transplantation: Just a Fancy Trend? Journal of Pediatric Gastroenterology and Nutrition, 61, 4-7. http://dx.doi.org/10.1097/mpg.0000000000000816 